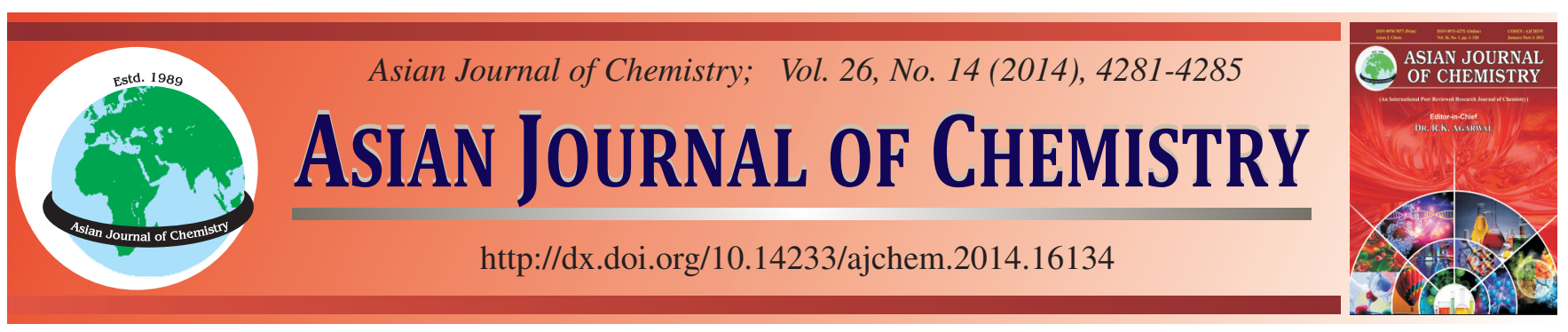

\title{
Effect of High Current Density in Electrocoagulation Process for Sewage Treatment
}

\author{
M. Nasrullah, Md. Nurul Islam Siddique and A.W. Zularisam*
}

Faculty of Civil Engineering and Earth Resources, University Malaysia Pahang, 26300 Gambang, Kuantan, Pahang, Malaysia

*Corresponding author: Fax: +60 95 492998; Tel: +60 95 493006; E-mail: zularisam@ump.edu.my

\begin{abstract}
Treatment of sewage wastewater by electrocoagulation with high cell current densities $\left(605 \mathrm{~A} / \mathrm{m}^{2}, 908 \mathrm{~A} / \mathrm{m}^{2}, 1211 \mathrm{~A} / \mathrm{m}^{2}, 1513 \mathrm{~A} / \mathrm{m}^{2}\right.$ and $1816 \mathrm{~A} / \mathrm{m}^{2}$ ) using stainless steel, iron and aluminum electrodes were studied. High current densities applied were very effective for the removal of chemical oxygen demand, biochemical oxygen demand and suspended solid in $0.5 \mathrm{~h}$. In the electrocoagulation of sewage wastewater, the effect of electrode material, current densities, electrocoagulation time, inter-electrode distance and initial pH were examined. The optimum operating range for each operating variable was experimentally determined in order to provide an economical and effective treatment for the sewage wastewater. Therefore, the optimum condition for this treatment is in $0.5 \mathrm{~h}$, by using stainless steel electrode, at $1816 \mathrm{~A} / \mathrm{m}^{2}$, in $\mathrm{pH} 7$ and $10 \mathrm{~mm}$ electrode distances. The optimum treatment condition reduced chemical oxygen demand by $98.07 \%$, biochemical oxygen demand by $98.07 \%$ and suspended solid by $97.64 \%$ and the anode loss during the experiment was $9.2 \times 10^{2}$ g.
\end{abstract}

Keywords: Electrocoagulation, Sewage wastewater, Chemical oxygen demand, Biochemical oxygen demand, Suspended solid.

\section{INTRODUCTION}

Sewage is the main point-source pollutant on a global scale ${ }^{1}$. Sewage, on the one hand, normally contained of biological, chemical and physical composition which is usually high in biochemical oxygen demand, chemical oxygen demand and suspended solid. So, direct discharge of raw or improper treated sewage into the water body is one of the main sources of pollution on a global scale ${ }^{1}$. There are two main objectives of wastewater treatment, one is protecting the environment and the other one is conserving fresh water resources ${ }^{2}$. These days, various physiochemical and biological technique have been employed to treat sewage water such as aerobic and anaerobic biological treatment, membrane filtration, adsorption, chemical coagulation and many others methods. Although the treatment techniques that mentioned above can be applied as the efficient methods, either they took a long period of time or needed a large amount of chemical substance, both ways are less effective in treating sewage water where it requires a short time treatment and an environmental compatibility with free chemical effect. Simple, affordable and efficient sewage wastewater treatment systems are urgently needed in developing countries because most of the conventional technologies currently in use in industrialized nations are too expensive and complex ${ }^{3}$.

Electrocoagulation is one of the simple methods to treat wastewater efficiently ${ }^{4}$. This electrochemical treatment seems to be a promising treatment method due to its high effec- tiveness, its lower maintenance cost, less need for labor and rapid achievement of results ${ }^{5}$. In the past few decades, several workers shown that the electrocoagulation is a promising treatment method and effectively potential to treat verity type of wastewaters including dyes wastewater ${ }^{6-8}$, tannery wastewater ${ }^{9}$, restaurant wastewater ${ }^{4}$, palm oil mill effluent ${ }^{6}$, food wastewater ${ }^{7}$, potato chip manufacturing wastewater ${ }^{8}$, urban wastewater $^{9}$ and removing heavy metals ${ }^{10-19}$.

Electrocoagulation treatment methods offer an alternative to the use of chemical coagulant such as metal salts or polymers for breaking the pollutants because during the electrocoagulation process, the electrode can generate coagulated species and metal hydroxides that destabilize and aggregate the suspended particles and precipitate. The hydrogen gas released from cathode would also help to float the flocculated particles out of the water ${ }^{20}$.

\section{EXPERIMENTAL}

Sample collection and characterization: Sewage wastewater was obtained from the first untreated pond at Indah Water Konsortium (IWK) which located at Indera Mahkota, Kuantan, Pahang, Malaysia. The composition of wastewater then characterized to identify the $\mathrm{pH}$, suspended solids, chemical oxygen demand, biochemical oxygen demand.

Experimental device: The batch experimental setup is schematically shown in Fig. 1. The electrochemical unit consists of an electrocoagulation cell, a D.C power supply and 
the electrodes (stainless steel, aluminum and iron). There are two monopolar electrodes having same dimension $(120 \mathrm{~mm}$ $\times 100 \mathrm{~mm} \times 2 \mathrm{~mm}$ ) as an anode and a cathode which spacing of 10, 20, 30 and $40 \mathrm{~mm}$ (depending on experiment) between each other. The total effective electrode was $1.652 \times 10^{-2} \mathrm{~m}^{2}$. In order to maintain an unchanged composition and avoid the association of the flocs in the solution, the stirrer was turned on and set at $80 \mathrm{rpm}$. All the electrodes were washed with dilute $\mathrm{HCl}$ before every experiments conducted. Every experiment was performed at the room temperature.

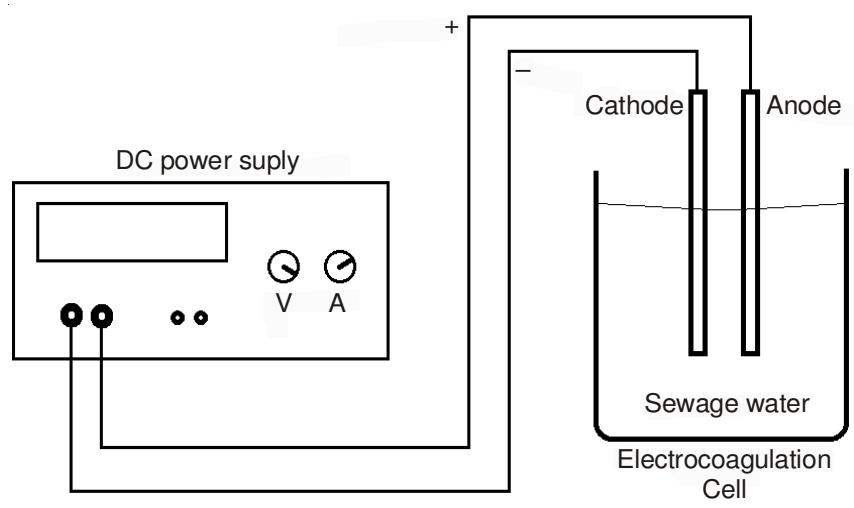

Fig. 1. Schematic diagram of experimental setup

The experiments were carried out in a batch mode. For each experiment, a sewage wastewater sample of 1 liter was collected in the electrochemical cell with two electrodes dipped into the sample. Six different of high current densities; 605, $908,1211,1513$ and $1816 \mathrm{~A} / \mathrm{m}^{2}$ were applied. In each current density applied, contact time of 5, 10, 15, 20, 25 and 30 were used. Therefore, a total of 17 experiments were carried out to determine the effect of electrode material, current densities, electrocoagulation time, inter-electrode distance and initial $\mathrm{pH}$. After the experiment, the treated sample was then kept undisturbed for $20 \mathrm{~min}$ in order to allow the flocks to settle. Subsequently, after settling the sample of supernatant was collected to perform the analysis of suspended solid, chemical oxygen demand and biochemical oxygen demand.

\section{RESULTS AND DISCUSSION}

Characteristic of sewage wastewater: Table-1 shows the characteristic of the sewage wastewater sample used before the treatment. As observed, the average chemical oxygen demand, biochemical oxygen demand and suspended solid concentration is in medium concentration which is 466, 259 and $297 \mathrm{mg} / \mathrm{L}$, respectively and the value of $\mathrm{pH}$ is 7.6.

\begin{tabular}{cc} 
TABLE-1 & \\
CHARACTERISTIC OF RAW SEWAGE WASTEWATER \\
\hline Parameter & Value \\
\hline Chemical oxygen demand (mg/L) & 466 \\
Biochemical oxygen demand (mg/L) & 259 \\
Suspended solid (mg/L) & 297 \\
$\mathrm{pH}$ & 7.6 \\
\hline
\end{tabular}

Effect of electrode material: Electrode assembles as the heart of the electrocoagulation process. Therefore, the appropriate selection of its materials is highly concerned. In this experiment, the stainless steel, iron and aluminum electrode were used as these types of electrode are proven effective to treat wastewater. The experiment was first running in $0.5 \mathrm{~h}$ at $1816 \mathrm{~A} / \mathrm{m}^{2}$ current density by using different types of electrode to obtain the best electrode in sewage wastewater treatment. Fig. 2 compares the treatment efficiency for these three kinds of electrodes under the same current density.

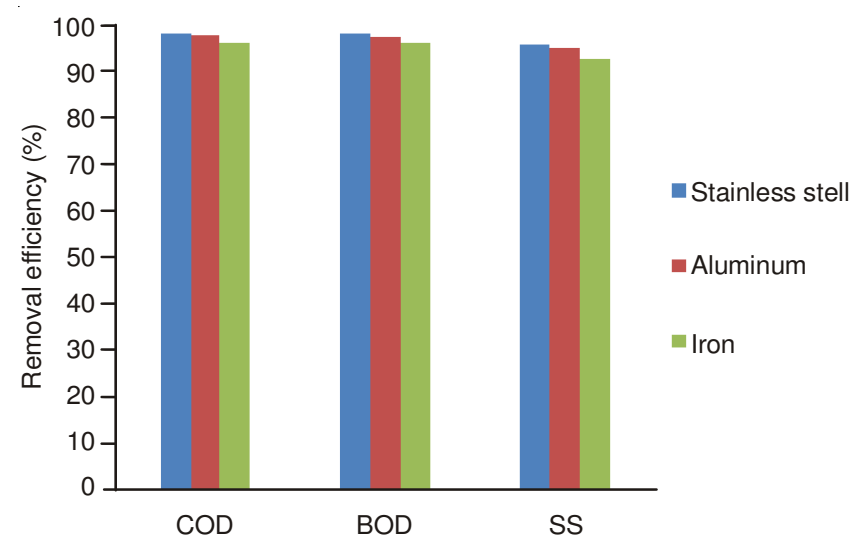

Fig. 2. Effect of electrode material with current density $1816 \mathrm{~A} / \mathrm{m}^{2}$, time $0.5 \mathrm{~h}, \mathrm{pH} 7$, interelectrode distance $10 \mathrm{~mm}$

The results indicated that for sewage wastewater, the stainless steel electrode was more effective than the iron and aluminum electrode, which can reduce chemical oxygen demand, biochemical oxygen demand and suspended solid by $98.07,98.07$ and $95.69 \% 0.5 \mathrm{~h}$ of treatment. While, by using iron as the electrode, percentage of chemical oxygen demand, biochemical oxygen demand and suspended solid removal is $96.14,96.14$ and $92.55 \%$, which a little bit lower than stainless steel. Besides, by using iron electrodes, the treating solution begins to change into greenish color after $5 \mathrm{~min}$ and then switch into brownish color a few minutes later during treatment. The green color must be due to $\mathrm{Fe}^{2+}$ and the brown color is $\mathrm{Fe}(\mathrm{III})$. $\mathrm{Fe}$ (II) can be easily oxidized into $\mathrm{Fe}(\mathrm{III})$. $\mathrm{Fe}(\mathrm{III})$ usually exist in the form of $\mathrm{Fe}(\mathrm{OH})_{3}$ which is fine particles and hard to precipitate. So iron electrode is not suitable to be used in this process. By using aluminum as electrode, the percentage of chemical oxygen demand, biochemical oxygen demand and suspended solid removal is 97.64, 96.14 and 94.9 $\%$, respectively. Although the treatment by aluminum electrode is almost about the same as the stainless steel electrode, it also not suitable in this experiments because aluminum electrode leave a thick turbidly sludge in the solution. Therefore, all subsequent experiments were carried out with stainless steel electrode.

Effect of current density: In all the electrocoagulation process, current density is the most important parameter in controlling the reaction rate. Rising current density resulted to an increase in the removal efficiency of chemical oxygen demand, biochemical oxygen demand, suspended solid. Fig. 3 shows the removal efficiency of chemical oxygen demand, biochemical oxygen demand and suspended solid against current density applied to the stainless steel electrodes in the electrocoagulation process.

When the current density increases, the efficiency of ion production in anode and cathode also increase, leading to the 


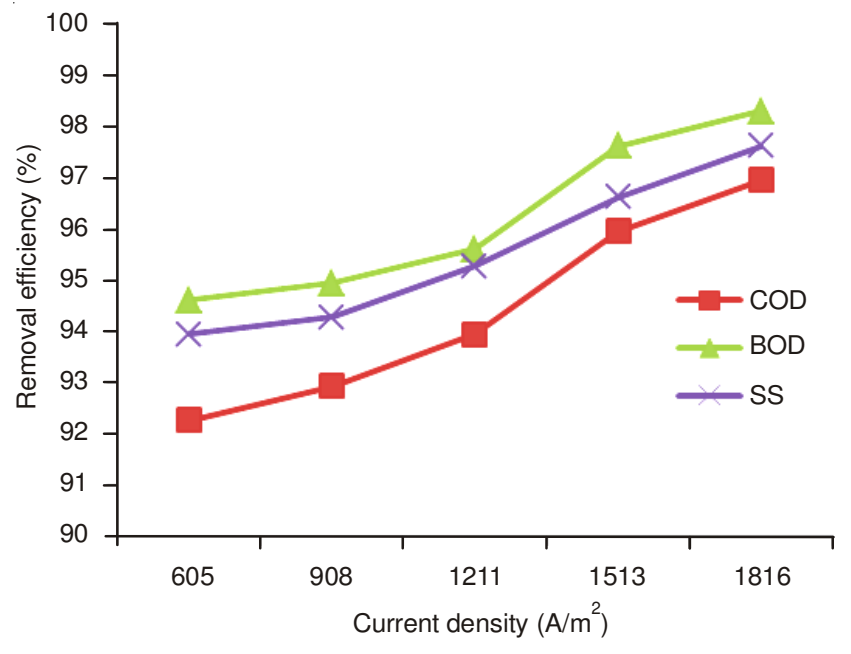

Fig. 3. Effect of current density on removal efficiency of chemical oxygen demand (COD), biochemical oxygen demand (BOD) and suspended solid (SS) using stainless steel electrode, time $0.5 \mathrm{~h}, \mathrm{pH} 7$ and interelectrode distance $10 \mathrm{~mm}$

flock production increment. So that, $96,98.3$ and $97.6 \%$ of chemical oxygen demand, biochemical oxygen demand and suspended solid percentage of removal was obtained by using $1816 \mathrm{~A} / \mathrm{m}^{2}$ during $0.5 \mathrm{~h}$ of electrocoagulation process compared to the $92.2,94.6$ and $94 \%$ of chemical oxygen demand, biochemical oxygen demand and suspended solid respectively by using only $605 \mathrm{~A} / \mathrm{m}^{2}$. The optimum of current density of $1816 \mathrm{~A} / \mathrm{m}^{2}$ was used for this treatment in $0.5 \mathrm{~h}$.

Effect of electrolysis time: As shown in Fig. 4, as the time of electrolysis increase comparable changes in the removal efficiency of chemical oxygen demand, biochemical oxygen demand and suspended solid are observed. Reactive time also influence the treatment efficiency of electrocoagulation process because the more time consume, the more production rate of hydroxyl and metal ion are produced on the electrodes.

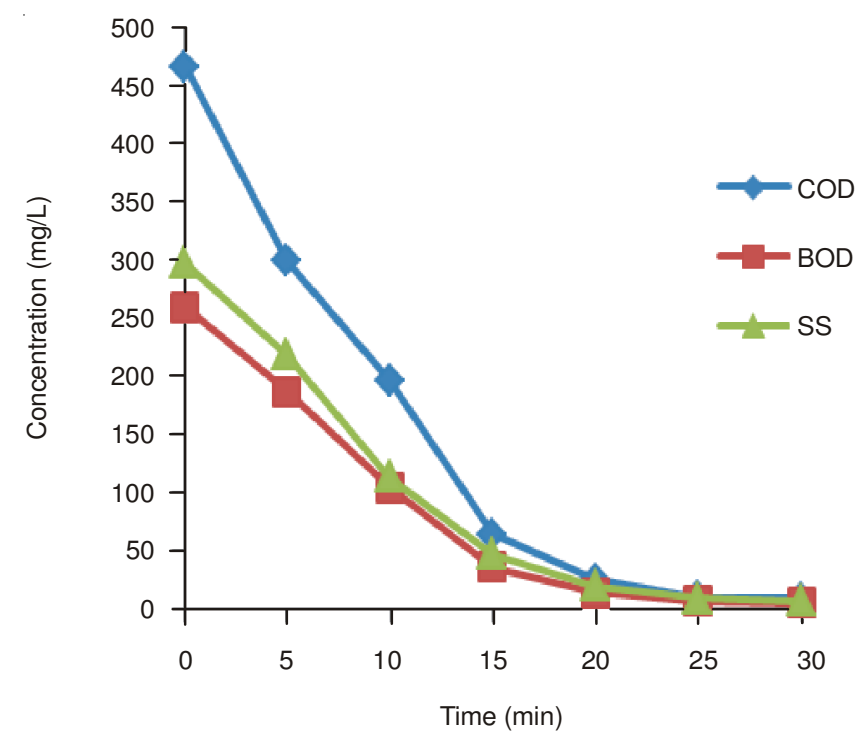

Fig. 4. Effect of time on chemical oxygen demand (COD), biochemical oxygen demand (BOD) and suspended solid (SS) removal using stainless steel electrode, current density $1816 \mathrm{~A} / \mathrm{m}^{2}, \mathrm{pH} 7$ and interelectrode distance $10 \mathrm{~mm}$
The effect of time was studied at constant current density of $1816 \mathrm{~A} / \mathrm{m}^{2}$. In this experiment, two stages have been going through by electrocoagulation process. The first stage is usually short, whereas the second one is taking relatively long time consumed. According to the result showed in Fig. 4, 15 min of operating time is sufficient for nearly complete treatment efficiency of chemical oxygen demand, biochemical oxygen demand and suspended solid. Treatment efficiency remains almost constant and has insignificant improvement above 20 min. Therefore, the optimum electrolysis time was $15 \mathrm{~min}$.

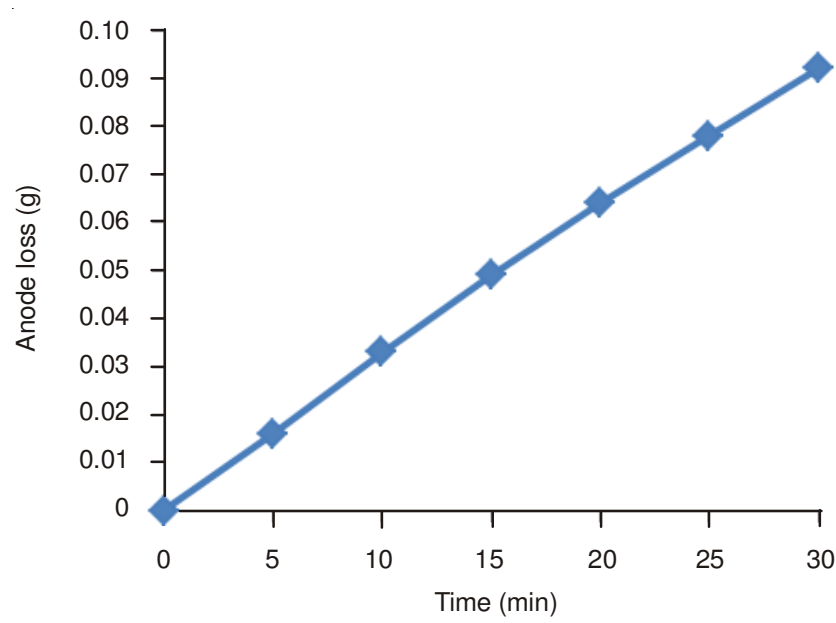

Fig. 5. Wight of stainless steel anode loss during electrocoagulation, at current density $1816 \mathrm{~A} / \mathrm{m}^{2}, \mathrm{pH} 7$, interelectrode distance $10 \mathrm{~mm}$, in $1 \mathrm{~L}$ sewage wastewater

Electrode consumptions are proportional to the operating time. Fig. 5 showed the electrode consumption increased almost steadily every minute. Increasing in time from 5 to 30 min resulted to a decreasing weight of cathode from 88.432 to $88.356 \mathrm{~g}$ stainless steel anode which is increment average of anode consumption is about $15 \mathrm{mg} / \mathrm{L}$ sewage wastewater every $5 \mathrm{~min}$. Therefore, this result indicates that retention time is very important parameter because it affects the economic applicability of electrocoagulation process in treatment of sewage wastewater.

Effect of inter electrode distance: The effect of inter electrode distance does not show a significant result in this experiment. However, as shown in Fig. 6, when inter electrode distance increases, the efficiency of chemical oxygen demand, biochemical oxygen demand and suspended solid removal decrease slightly because the rate of electron transfer is become slower. Variations of the percentage removal with inter electrode distance is shown in Fig. 6.

Fig. 6 suggested that the removal efficiency slightly decreases when electrode distance increases. For chemical oxygen demand, removal efficiency decreases from $98.07 \%$ at $10 \mathrm{~mm}$ electrode distances to $96.35 \%$ at $40 \mathrm{~mm}$ electrode distances. For biochemical oxygen demand, the removal efficiency is almost the same as chemical oxygen demand which is from $98.07 \%$ at $10 \mathrm{~mm}$ to $96.53 \%$ at $40 \mathrm{~mm}$ electrode distance. For suspended solid, the removal efficiency decreases from $97.64 \%$ at $10 \mathrm{~mm}$ to $95.62 \%$ at $40 \mathrm{~mm}$ electrode distances. The increase of inter electrode distance make the cell potential $(\mathrm{V})$ increases which also increases the resistance 


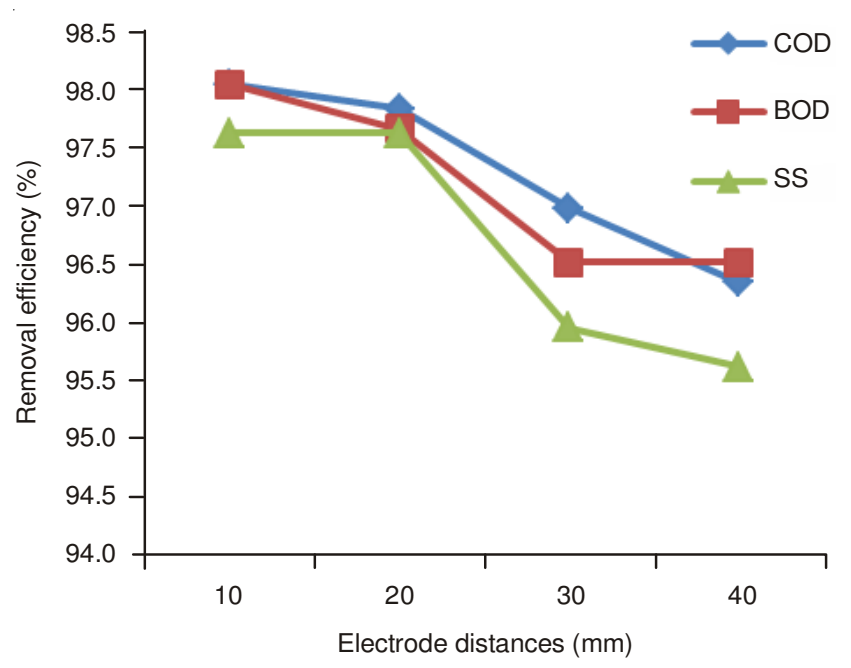

Fig. 6. Effect of electrode distance on removal efficiency, using stainless steel electrode, at current density $1816 \mathrm{~A} / \mathrm{m}^{2}, \mathrm{pH} 7$, time $0.5 \mathrm{~h}$

and adversely affect the sewage wastewater treatment. According to Ohm's law, the amount of electric current through a metal conductor in a circuit is directly proportional to the voltage impressed across it, for any given temperature. This relationship can be expressed as:

$$
\mathrm{V}=\mathrm{IR}
$$

Ohmic potential drop or IR drop can have a significant influence on electrochemical measurements. Ohmic potential drop is potential drop due to solution resistance. The difference in potential required to move ions through the solution. The variation in IR drop is governed by equation below ${ }^{21}$ :

$$
\eta I R=I \cdot \frac{d}{D \cdot \kappa}
$$

Where:

$\mathrm{I}=$ current $(\mathrm{A})$

$\mathrm{d}=$ distance between cathode and anode $(\mathrm{m})$

$\mathrm{A}=$ active anode surface $\left(\mathrm{m}^{2}\right)$

$\kappa=$ specific conductivity $\left(10^{3} \mathrm{mS} / \mathrm{m}\right)$

From the equation above infers that IR drop increase by increasing the distance of the electrodes. During the experiment, the current suddenly drop after some time, so applied voltage has been increase in order to maintain the constant current. This situation occurs maybe due to the rising of Ohmic loss (IR drop) which lead to the rate of anodic oxidation inhibited. Therefore, the increase of IR drop by increase the distance between anode and cathode is not recommended in electrocoagulation process.

Effect of pH: It has been established from the previous studies that $\mathrm{pH}$ is an important variable influencing the treatment performance of the electrocoagulation process ${ }^{21,22}$. In order to examine its effect, the sewage ${ }^{23,24}$ wastewater was adjusted to the desired $\mathrm{pH}$ by using potassium hydroxide and sulfuric acid.

Fig. 7 showed the effect of $\mathrm{pH}$ on chemical oxygen demand, biochemical oxygen demand and suspended solid removal efficiency. The removal efficiency is very low in acidic electrolyte which can only remove $93.82,91.58$ and $93.99 \%$ for chemical oxygen demand, biochemical oxygen demand and

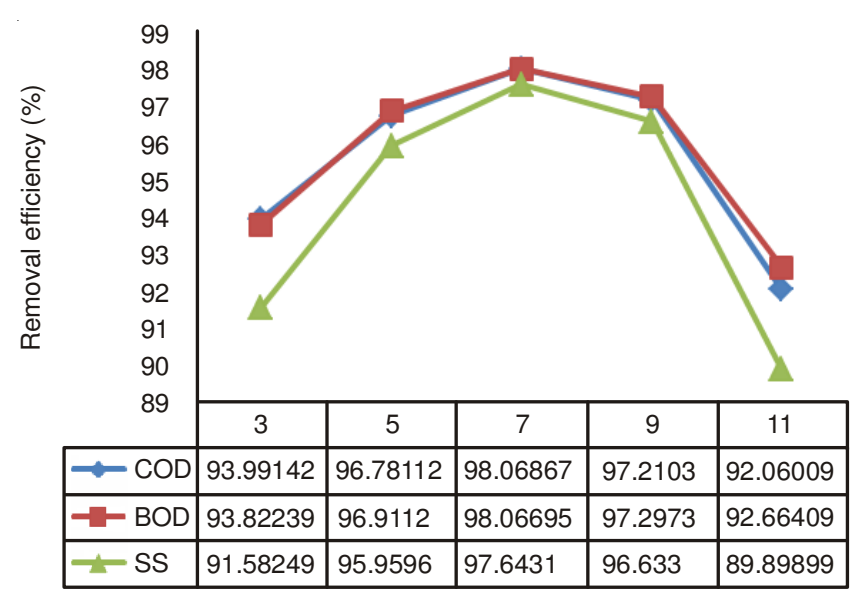

Fig. 7. Effect of $\mathrm{pH}$ on removal efficiency, using stainless steel electrode, at current density $1816 \mathrm{~A} / \mathrm{m} 2,0.5 \mathrm{~h}, 10 \mathrm{~mm}$ electrode distances

suspended solid respectively at $\mathrm{pH}$ 3. Meanwhile, in alkaline solution, the removal efficiency is also very low which is for chemical oxygen demand, biochemical oxygen demand and suspended solid is $92.06,92.66$ and $89.9 \%$, respectively at $\mathrm{pH} 11$. However, in neutral electrolyte solution, chemical oxygen demand, biochemical oxygen demand and suspended solid removal efficiency is $98.07,98.07$ and $97.64 \%$, respectively. From the Fig. 7, it can be concluded that the optimum pH values appeared between 7 and 9 which provide an economical and effective treatment for the sewage wastewater in practical $^{25,26}$.

\section{Conclusion}

Electrocoagulation was approved as an effective method for the reduction of chemical oxygen demand, biochemical oxygen demand and suspended solid in sewage wastewater. In this treatment, the effect of electrocoagulation on the removal efficiency of chemical oxygen demand, biochemical oxygen demand and suspended solid point out to be dependent on the amount of ion release by electrode for the higher current densities of $605,908,1211,1513$ and $1816 \mathrm{~A} / \mathrm{m}^{2}$, meaning that, as the higher current density been given, the higher amount of metal ion been generated, leading to higher treatment efficiency. The influence of various operational variables such as current density, type of electrode material, electrocoagulation time, $\mathrm{pH}$ and inter electrode distance on removal of chemical oxygen demand, biochemical oxygen demand and suspended solid was investigated. The result showed that the removal of chemical oxygen demand, biochemical oxygen demand and suspended solid increase with the increase of every operational parameter stated except for $\mathrm{pH}$ and inter electrode distance. The highest removal efficiency of chemical oxygen demand by $98.07 \%$, biochemical oxygen demand by $98.07 \%$ and suspended solid by $97.64 \%$ occurred at $1816 \mathrm{~A} / \mathrm{m}^{2}$ current density, $10 \mathrm{~mm}$ inter electrode distances and $\mathrm{pH} 7 \mathrm{in} 0.5 \mathrm{~h}$ of operating time by using stainless steel electrode.

\section{ACKNOWLEDGEMENTS}

The authors thank Faculty of Civil Engineering and Earth Resources, University Malaysia Pahang, for providing continuous laboratory facility. The present research was made possible availing facility provided by RDU-0903113. 


\section{REFERENCES}

1. H. Gijzen, Water Sci. Technol., 45, 321 (2002).

2. A.A. Bukhari, Bioresour. Technol., 99, 914 (2008).

3. P. Grau, Water Sci. Technol., 33, 39 (1996).

4. X. Chen, G. Chen and P.L. Yue, Sep. Purif. Technol., 19, 65 (2000).

5. C. Feng, N. Sugiura, S. Shimada and T. Maekawa, J. Hazard. Mater., 103, 65 (2003).

6. C. Phalakornkule, J. Mangmeemak, K. Intrachod and B. Nuntakumjorn, Sci. Asia, 36, 142 (2010).

7. Y.M. Zheng and J.P. Chen, Handbook of Advanced Industrial and Hazardous Wastes Treatment-II, Taylor and Francis \& CRC Press, p. 30 (2008).

8. M. Kobya, H. Hiz, E. Senturk, C. Aydiner and E. Demirbas, Desalination, 190, 201 (2006).

9. M.F. Pouet and A. Grasmick, Water Sci. Technol., 31, 275 (1995).

10. I. Kabdasli, T. Arslan, T. Olmez-Hanci, I. Arslan-Alaton and O. Tünay, J. Hazard. Mater., 165, 838 (2009).

11. F. Akbal and S. Camci, Desalination, 269, 214 (2011).

12. Ö. Hanay and H. Hasar, J. Hazard. Mater., 189, 572 (2011).

13. A. Shafaei, E. Pajootan, M. Nikazar and M. Arami, Desalination, 279, 121 (2011).

14. A. Shafaei, M. Rezayee, M. Arami and M. Nikazar, Desalination, 260, 23 (2010).
15. B. Al-Aji, Y. Yavuz and A.S. Koparal, Sep. Purif. Technol., 86, 248 (2012).

16. A. Shafaei, M. Rezaie and M. Nikazar, Chem. Eng. Process., 50, 1115 (2011).

17. I. Heidmann and M. Calmano, J. Hazard. Mater., 152, 934 (2008).

18. N. Meunier, P. Drogui, G. Mercier and J.F. Blais, Sep. Purif. Technol., 137, 581 (2006).

19. B. Merzouk, B. Gourich, A. Sekki, K. Madani and M. Chibane, J. Hazard. Mater., 164, 215 (2009).

20. M. Kobya, E. Demirbas, O.T. Can and M. Bayramoglu, J. Hazard. Mater., 132, 183 (2006).

21. E.A. Vik, D.A. Carlson, A.S. Eikum and E.T. Gjessing, Water Res., 18, 1355 (1984).

22. N. Daneshvar, A. Oladegaragoze and N. Djafarzadeh, J. Hazard. Mater., 129, 116 (2006).

23. Y. Yuan, T. Yuan, D. Wang, J. Tang and S. Zhou, Bioresour. Technol., 144, 115 (2013).

24. J.P.S. Sidhu, W. Ahmed, W. Gernjak, R. Aryal, D. McCarthy, A. Palmer, P. Kolotelo and S. Toze, Sci. Total Environ., 463-464, 488 (2013).

25. S.M. Rhind, C.E. Kyle, H. Ruffie, E. Calmettes, M. Osprey, Z.L. Zhang, D. Hamilton and C. McKenzie, Environ. Pollut., 181, 262 (2013).

26. Y. Sun, H. Huang, Y. Sun, C. Wang, X.L. Shi, H.Y. Hu, T. Kameya and K. Fujie, Environ. Pollut., 180, 339 (2013). 